\section{BMJ Open Respiratory Research}

\title{
Concordance of opinions between patients and physicians and their relationship with symptomatic control and future risk in patients with moderate-severe asthma
}

\author{
Astrid Crespo-Lessmann, ${ }^{1}$ Vicente Plaza, ${ }^{1}$ Francisco-Javier González-Barcala, ${ }^{2}$ \\ Toni Fernández-Sánchez, ${ }^{3}$ Joaquín Sastre, ${ }^{4}$ on behalf of The CONCORD Study \\ Group
}

To cite: Crespo-Lessmann A, Plaza V, González-Barcala F-J, et al. Concordance of opinions between patients and physicians and their relationship with symptomatic control and future risk in patients with moderate-severe asthma. BMJ Open Resp Res 2017;4:e000189. doi:10.1136/ bmjresp-2017-000189

Received 14 March 2017 Revised 26 July 2017 Accepted 9 August 2017

\section{(1) CrossMark}

For numbered affiliations see end of article.

Correspondence to

Dr Astrid Crespo-

Lessmann, Service of PneumologyHospital de la Santa Ceu i Sant Pau, Institute of Sant Pau \& Biomedical Research (IBB Sant Pau), Universitat Autònoma de Barcelona, Centro de Investigación Biomédica en Red de Enfermedades Respiratorias (CIBERES), Barcelona, Spain; acrespo@santpau.cat

\section{ABSTRACT}

Introduction Differences between the opinions of patients and physicians on the impact of asthma are common. We hypothesised that patient-physician discordance may negatively affect asthma outcome.

Methods A total of 2902 patients ( $61 \%$ women, mean age 47 years) with moderate-severe asthma and 231 physicians participated in a prospective study. At the baseline visit, data on demographics, clinical variables, degree of asthma control according to the Asthma Control Test (ACT), basic spirometry and the Hospital Anxiety and Depression Scale (HADS) were collected and an ad hoc questionnaire was completed that allowed the degree of concordance between doctors and patients to be assessed. A scheduled telephone call after 3 months was used to elicit the ACT score and the future risk of asthma. At the final visit at 6 months, the following data were recorded: ACT score, spirometry, HADS score and an ad hoc questionnaire to assess the agreement between the doctor and the patient. Changes in study variables according to patient-physician concordance or discordance were analysed.

Results The rate of patient-physician discordance was $27.2 \%$, with overestimation of disease impact by the physician in $12.3 \%$ and underestimation in $14.9 \%$. Patient-physician opinion discordance, particularly in the case of physicians underestimating the impact of asthma, showed worse results with statistically significant differences in ACT score, a higher percentage of patients with poor asthma control and lower HADS scores. The need for hospital and emergency department admissions was also higher.

Conclusion Patient-physician opinion discordance may be contributing to lower symptomatic control and increased future risk, with a higher impact when physicians underestimate the impact of asthma on their patients.

\section{INTRODUCTION}

Asthma is a heterogeneous chronic inflammatory airways disease that represents a major public health problem, with a high

\section{Key messages}

Differences between the opinions of patients and physicians on the impact of asthma are common.

- Patient-physician discordance may negatively affect asthma control and future risk.

> Physicians' underestimations of asthma were associated with worse outcomes.

- Asthma education programmes should address patients' and doctors' discordances.

prevalence and increasing trends in morbidity and mortality. ${ }^{1}$ Clinical practice guidelines for the management of asthma establish, as a primary objective of treatment, to achieve and maintain good control of symptoms and lung function, as well as to prevent future risk, including severe exacerbations, deterioration of lung function and adverse effects of treatment. $^{1-3}$

Although good control of asthma can be achieved in many patients, real-life studies have shown that asthma is frequently poorly controlled. $^{4-6}$ Lack of patient involvement in treatment, partially attributed to poor communication with their physician, has been put forward as one of the reasons for inappropriate management of asthma. ${ }^{7-10}$ Ensuring the necessary involvement of patients in their treatment, which enables them to learn about key aspects of asthma including how to adapt their lifestyle to the disease and awareness of the expected benefits of treatment, improves the effectiveness of the patient-doctor relationship and consequently the adherence to asthma medication regimens. For all of these aspects, asthma clinical practice guidelines recommend maximising concordance between patients and healthcare professionals. ${ }^{1-3}$ The 
term 'concordance' in different studies encompasses the level of agreement between physicians and patients in terms of general expectations from treatment and with regard to the disease. This means that patients should understand the potential benefits and limitations of treatment as well as adverse events, whereas physicians ought to understand the perceptions and concerns of patients. ${ }^{11}$ Therefore, the term includes a process in which physicians and patients agree on therapeutic decisions, recognise that they may have different perspectives, and the need to work together in the management of the disease to improve mutual understanding. ${ }^{12}$ In fact, unrealistically high or low expectations among patients concerning improvement of disease or the care they can receive from professionals may negatively affect patient-physician concordance. ${ }^{13}$

Despite the potential impact of misunderstandings between patients and physicians, only a few studies have examined concordance between patients' and their doctors' expectations in asthma. ${ }^{14}{ }^{15}$ In a previous study of 1160 patients with asthma and 300 pulmonologists, the rate of patient-pulmonologist concordance on disease impact on patient daily life was $57 \%$, with physicians underestimating the impact (compared with patients) in $26 \%$ of cases, and in patient satisfaction with treatment of $56 \% .^{11}$ However, no studies have previously assessed patients' and doctors' misperceptions in relation to control of asthma symptoms, future risk and comorbidities such as anxiety and depression. Anxiety and depression have been shown to correlate with poorly controlled asthma, reduced quality of life and increased healthcare use. ${ }^{16-19}$

The present prospective observational study was conducted to assess the impact of discordance in patients' and physicians' opinions on control of asthma symptoms, future risk and anxiety and depression. We hypothesised that patient-physician discordance may negatively affect asthma outcome, which consequently would reinforce the need to improve patient-physician concordance as a behavioural aspect of asthma education.

\section{METHODS}

\section{Study design}

This was a prospective, observational, multicentre study with a follow-up period of 6 months. The study was carried out in 174 hospitals throughout Spain belonging to the public National Healthcare System. A total of 231 investigators were recruited for the study, 121 of whom were specialists in allergology, 103 in pneumology, 6 in general internal medicine and 1 in emergency medicine.

\section{Ethical aspects}

The study was promoted by Mundipharma Pharmaceuticals (Madrid, Spain). It was carried out in accordance with the 1991 International Guidelines for Ethical Review of Epidemiological Studies and complied with the updated version of the Declaration of Helsinki and Order SAS/3470/2009. The study was submitted to the Spanish Agency of Medicines and Health Products for classification, and the protocol was approved by the Ethics Committee of the participating hospitals of the study coordinators. Written informed consent was obtained from all patients. Study data were entered in a database owned by Mundipharma Pharmaceuticals, who were responsible to the Spanish Data Protection Agency (AEPD) and ensured confidentiality of data according to the Spanish law on Personal Data Protection (Organic Act 15/1999 December 13).

\section{Population}

Patients who attended the first visit with their specialist doctor were recruited from the outpatient clinics of the participating hospitals. The inclusion criteria were: previously diagnosed with asthma, male and female patients aged $\geq 18$ years, moderate or severe persistent asthma (step $\geq 3$ according to the Spanish Guidelines for the Management of Asthma (GEMA)), ${ }^{1}$ stable disease (patients had had no asthmatic exacerbations or changes in usual asthma treatment in the last 6 months), agreed to take part in the study and provided written informed consent. The diagnosis of asthma was based on patients reporting symptoms consistent with asthma (coughing, wheezing, chest tightness, shortness of breath) and a positive bronchodilator test (increase of $\geq 12 \%$ and $\geq 200 \mathrm{~mL}$ as an absolute value compared with baseline in either forced expiratory flow in $1 \mathrm{~s}\left(\mathrm{FEV}_{1}\right)$ or forced vital capacity (FVC)) or a daily peak expiratory flow variability $>20 \%$, or a positive methacholine challenge test documented in the case history. ${ }^{20}$ Patients were excluded from the study if they had a concomitant disease (sarcoidosis, lung cancer, pulmonary tuberculosis, bronchiectasis, nephropathy, rheumatic or liver disease), significant comorbidity that could affect the study results in the physician's judgement or a cognitive impairment that could limit their comprehension of the subject under study or their ability to participate.

\section{Methodology}

The study included a baseline visit, a telephone assessment 3 months later and a final visit at 6 months. At baseline, the following data were recorded for each patient: demographics (age and sex); clinical variables (level of education, marital status, smoking status, number of years since onset of asthma, severity of asthma); degree of asthma control according to the Asthma Control Test $(\mathrm{ACT})^{21}$ (an ACT score $\geq 20$ identified well-controlled asthma $)^{3}$; basic spirometry using the predicted values for the Mediterranean population ${ }^{22}$; an ad hoc questionnaire composed of 10 items about the impact of the disease on patient activities of daily living and future asthma-related risk; and the Hospital Anxiety and Depression Scale (HADS). ${ }^{23}$ Asthma control (ACT score) and future risk were also assessed at the 3-month telephone call.

At the final visit at 6 months, data recorded were the following: ACT score, lung function (spirometry), HADS score, an ad hoc questionnaire composed of 10 
Table 1 Description of the 10-item ad hoc questionnaire to assess the impact of asthma on daily living activities completed by patients and physicians

Scores (from $0=$ no impact to $10=$ severe impact)

Items

$\begin{array}{lllllllllll}0 & 1 & 2 & 3 & 4 & 5 & 6 & 7 & 8 & 9 & 10\end{array}$

1. Having independence in self-care (personal hygiene/grooming, dressing/undressing, eating, etc)

2. Doing housework (cleaning including floors, making beds, etc)

3. Performing other normal daily activities (regular commitments, going out, hobbies, exercise, etc)

4. Performing sporadic leisure time activities (travelling, cinema/ theatre, sports, other hobbies, etc)

\section{Carrying out usual work tasks \\ 6. Maintaining normal social relationships}

7. Maintaining normal family relationships

8. Having an active sexual life (frequency of relations and satisfaction)

9. Economic burden of the disease on the family

10. Health-related quality of life

items about the impact of the disease on patient activities of daily living and future asthma-related risk. The HADS is a 14-item questionnaire, with seven items related to anxiety and seven items related to depression. Each item is scored from 0 to 3 , scores for each subscale ranging from 0 to 21 and scores for the entire scale (emotional distress) from 0 to 42, with higher scores indicating more distress. HADS scores in each construct are divided into normal (0-7), doubtful (8-10) and definite (11-21) cases. ${ }^{17}$ The ad hoc questionnaire was composed of 10 items about the impact of the disease on patient activities of daily living; each item was scored on a Likert scale ranging from 0 (no impact) to 10 (severe impact) (see table 1). The 10-item questionnaire on the impact of asthma on daily living was completed by the patients and also by the physicians using the information available in each patient's medical history and their knowledge of the case after seeing the patient. To use this questionnaire, this study took as reference the study by Urrutia et al. ${ }^{11}$ Physicians were blinded to the patients' responses to questions. The physicians were given access to the responses of their patients after completing the questionnaires and, subsequent to the visit, they completed the online database. Comparison of the responses of the physician and the patient was performed by external observers through online and deferred registration in order to assess the degree of concordance between doctors and patients. The future risk of asthma was assessed according to the concepts established by the Global Initiative for Asthma (GINA) ${ }^{3}$ and GEMA. ${ }^{1}$ These criteria are: (1) the number of severe asthma exacerbations in the previous 3 months (need for a short course of oral prednisone during a minimum of 3 days and/or visit to the emergency department and/or admission to the hospital); and (2) use of healthcare resources in the previous 3 months (visits to the primary care physician, specialist, nurse, emergency department and hospitalisations).

\section{Statistical analysis}

The sample size needed to allow evaluation of the main objective of the study was based on the study by Urrutia et $a{ }^{11}{ }^{11}$ In this cross-sectional design work, the level of concordance between patients and doctors ranged between $57 \%$ and $75 \%$. Therefore, for a type I error of 0.05 and amplitude of the $95 \%$ CI of $3.5 \%$, a total of 3075 patients would be needed in the case of $57 \%$ concordance (worst scenario). Since the patients had a follow-up of 6 months in the study, the sample size was increased to allow for possible losses in follow-up. A loss rate of $5 \%$ was assumed, so an attempt was made to include 3250 patients in the study. Categorical variables are expressed as absolute and relative frequencies and quantitative variables as mean, median, $\mathrm{SD}, \min , \max , \mathrm{Q} 1$ and $\mathrm{Q} 3$. To assess the level of agreement between patients and physicians in responses to the 10-item questionnaire of the impact of asthma on daily activities, an algorithm that classified cases into concordance or discordance of opinions was used. Patient-physician opinion agreement or concordance was established when the mean of the sum of scores of physicians' and patients' questionnaires was in the same quartile, and lack of agreement or discordance when they did not coincide in the same quartile. In case of discordance, underestimation or overestimation was considered when physicians scored below or above the patients' scores, respectively. The difference in the total scores of physicians and patients was used to generate a new continuous variable (the higher the score, the greater the disagreement), which was explored with other continuous variables. Categorical variables were compared with the $\mathrm{X}^{2}$ test and the Fisher exact test 
for independent samples, or the McNemar test for paired samples. Quantitative variables were compared with the Student t-test, the Mann-Whitney U test or the Wilcoxon rank-sum test. The analysis of variance (ANOVA) or the Kruskal-Wallis test was used for the comparison of three or more groups of continuous data. The relationship between two continuous variables was assessed using the Spearman rank-order correlation coefficient $(\rho)$. Statistical analysis was performed using the Statistical Package for Social Sciences (SPSS, Chicago, Illinois, USA) Version 22.0 for Windows. The threshold for statistical significance was set at $\mathrm{p}<0.05$.

\section{RESULTS}

Sociodemographic and clinical characteristics of patients

A total of 3183 patients diagnosed with asthma were included in the study, but $281(8.8 \%)$ failed to complete the 6-month follow-up. The main cause of patients' loss to follow-up was abandonment of the study (failure to attend the medical visit). Therefore, the study population consisted of 2902 patients (61.2\% women) with a mean (SD) age of 46.8 (16.7) years. Salient findings were as follows: $63.9 \%$ of patients were never smokers, $65.4 \%$ were married or lived with a partner and $31.7 \%$ had completed secondary education. Asthma-related data at baseline showed a poor control of symptoms in $75.3 \%$ of patients (ACT score <20), the mean (SD) forced expiratory volume in $1 \mathrm{~s}_{(}\left(\mathrm{FEV}_{1}\right)$ was $81.6(20.9) \%$ and persistent moderate asthma was diagnosed in $81 \%$ of patients. Anxiety and depression were present in $24.2 \%$ and $11.7 \%$ of patients, respectively. At 6 months there was a significant improvement in asthma control, degree of airways obstruction and anxiety and depression scores according to the HADS (table 2).

\section{Patient-physician opinion concordance/discordance}

At the follow-up visit at 6 months, discordance between patients' and physicians' opinions was found in 789 $(27.2 \%)$ cases. The impact of asthma on daily living was underestimated by the physician in $357(12.3 \%)$ cases

Table 2 Sociodemographic data, spirometry, level of control of asthma symptoms and anxiety/depression of study patients

\begin{tabular}{|c|c|c|c|c|}
\hline Variables & $\begin{array}{l}\text { Baseline visit } \\
(n=3183)\end{array}$ & $\begin{array}{l}\text { Telephone survey } \\
\text { at } 3 \text { months } \\
(\mathrm{n}=3057)\end{array}$ & $\begin{array}{l}\text { Final visit at } \\
6 \text { months } \\
(n=2902)\end{array}$ & $\begin{array}{l}\text { p Value (final } \\
\text { vs baseline } \\
\text { visits) }\end{array}$ \\
\hline \multicolumn{5}{|l|}{ Sociodemographic data } \\
\hline Women, n (\%) & $1948(61.2)$ & & & \\
\hline Age, years, mean (SD) & $46.8(16.7)$ & & & \\
\hline \multicolumn{5}{|l|}{ Smoking status } \\
\hline Current smoker & $391(12.3)$ & & & \\
\hline Ex-smoker & $757(23.8)$ & & & \\
\hline Never smoker & $2034(63.9)$ & & & \\
\hline \multicolumn{5}{|l|}{ Civil status } \\
\hline Married or lived with a partner & $2082(65.4)$ & & & \\
\hline Single & $820(25.8)$ & & & \\
\hline Separated or widowed & $281(8.8)$ & & & \\
\hline Years since asthma diagnosis, mean (SD) & $7.6(9.6)$ & & & \\
\hline \multicolumn{5}{|l|}{ Severity of asthma, n (\%) } \\
\hline Moderate & $2577(81.0)$ & & & \\
\hline Severe & $605(19.0)$ & & & \\
\hline Exacerbations in the last 6 months, mean (SD) & & & $2.3(1.8)$ & \\
\hline \multicolumn{5}{|l|}{ Asthma control and spirometry } \\
\hline ACT score, mean (SD) & $15.8(4.7)$ & $19.3(4.2)$ & $19.4(4.4)$ & $<0.001$ \\
\hline Patients with controlled asthma (ACT $\geq 20), n$ (\%) & $785(24.7)$ & $1700(55.6)$ & $1667(57.5)$ & $<0.001$ \\
\hline $\mathrm{FEV}_{1}, \%$, mean $(\mathrm{SD})$ & $81.6(20.9)$ & & $86.0(20.8)$ & $<0.001$ \\
\hline \multicolumn{5}{|l|}{ HADS } \\
\hline Anxiety subscale score, mean (SD) & $7.1(4.3)$ & & $5.9(4.2)$ & $<0.001$ \\
\hline Patients with anxiety (score $\geq 11$ ), $n$ (\%) & $769(24.2)$ & & 445 (15.3) & $<0.001$ \\
\hline Depression subscale score, mean (SD) & $5.2(4.1)$ & & $4-4(4.0)$ & $<0.001$ \\
\hline Patients with depression (score $\geq 11$ ), $\mathrm{n}(\%)$ & $373(11.7)$ & & $234(8.1)$ & $<0.001$ \\
\hline
\end{tabular}

$A C T$, asthma control test; FEV $_{1}$, forced expiratory volume in first second; HADS, Hospital Anxiety Depression Scale. 
and overestimated in the remaining 432 (14.9\%). As shown in table 3 , in the group with patient-physician discordance, in particular due to underestimation of the impact of the disease by physicians, poorer results of asthma outcome were obtained, with statistically significant differences in the control of symptoms (ACT score and percentage of patients with poorly controlled asthma) and level of anxiety and depression. Also, the amplitude of the difference between patients' and physicians' scores was significantly and negatively associated with asthma control (ACT test) $(\rho=-0.322, p<0.001)$ and significantly and positively associated with the number of exacerbations $(\rho=0.171, p<0.001)$ and overall HADS scores $(\rho=0.275, p<0.001)$.

\section{DISCUSSION}

This study shows that discordance in the opinion of patients with asthma and their physicians regarding the impact of disease on activities of daily living is relatively frequent (27.2\% of cases) and is associated with a poorer symptomatic control of asthma and also, in part, with a higher future risk, especially when the physician has underestimated the impact of the disease. This finding may have important implications in asthma education programmes, in which it seems necessary to include strategies for improving differences between patients and clinicians in their views regarding repercussions of the disease in daily life. It is possible that these differences of opinion may have implications for the difficulty in achieving good asthma control. Clinicians in their usual clinical practice should consider these results. New tools should be established in the consultation to improve this aspect.

Despite clinical practice guidelines with explicit recommendations for a stepwise approach tailored to disease severity $^{1-3}$ and validated instruments to assess the degree of asthma control, ${ }^{21} 2425$ different studies have shown that, in less than $40 \%$ of patients, asthma is well-controlled. ${ }^{26}{ }^{27}$ Patients with inadequately controlled asthma often have limited therapeutic options and remain at high risk of serious morbidity and mortality. ${ }^{28}$ However, patients' misperceptions regarding the presence of symptoms as indicative of poor asthma control is frequent. An online survey conducted among 8000 patients with asthma from 11 European countries showed interesting data. ${ }^{29}$ More than $80 \%$ of respondents considered their asthma to be controlled and over two-thirds did not regard their condition as serious, even among those whose asthma was uncontrolled according to the GINA criteria. ${ }^{3}$ Similarly, more than $80 \%$ of respondents who had experienced acute exacerbations (oral steroid use, emergency department visits or hospitalisations) in the previous year regarded their asthma as controlled. Of those who considered their asthma controlled, $55.5 \%$ had had symptoms that interfered with normal activities and $52.5 \%$ had awoken at night because of asthma in the previous week. Moreover, of those who regarded their asthma as not serious, $19.5 \%$ reported an asthma-related emergency department visit in the previous year. Educating patients will help to improve their understanding of asthma and enable them to work with their physician to manage their disease. ${ }^{29}$

It has been shown that patients, particularly those with severe and/or difficult asthma and poor control, underplay symptoms and do not discuss non-medical factors which may impact on asthma control in primary care consultations, ${ }^{4}$ so training physicians in the use of patient-centred communication skills may optimise asthma management in this setting. Moreover, poor professional-patient communication has been considered a reason for the poor uptake of self-management plans and guideline use in general practice and primary care. ${ }^{7}$ Irwin and Richardson ${ }^{8}$ concluded that patient-focused care communication, continuity of care and concordance (finding common ground) are highly relevant to the effective treatment of pulmonary disease and should be a key component of asthma management.

In a previous study of agreement between patients and pneumologists, patient-physician discordant rates of disease impact on daily life and patient satisfaction were significantly lower among patients with controlled asthma (29\% and $32.1 \%)$ than those with poorly controlled disease $(73.7 \%$ and $73.1 \%) .{ }^{11}$ In our study, patient-physician discordance was found in $27.2 \%$ of cases. The impact of asthma was overestimated by physicians in $12.3 \%$ of patients and underestimated in $14.9 \%$. Patient-physician opinion discordance affected negatively the degree of asthma control, particularly when the patient's status was underestimated by physicians. In addition, there was a significant negative correlation between patient-physician discordance and the ACT score.

Control of future risk includes the absence of severe exacerbation episodes and visits to the emergency department (or possible hospital admissions), prevention of progressive deterioration of pulmonary function and dose adjustment of asthma medications to minimise adverse effects. In the present study, the amplitude of the difference in scores of the 10-item questionnaire between patients and physicians was significantly correlated with the number of exacerbations.

Different studies support the view that there is an increase in psychiatric morbidity in patients with obstructive airways diseases. ${ }^{30-35}$ A study carried out in adults with clinically stable asthma showed a prevalence of $36.9 \%$ for anxiety and $11 \%$ for depression, ${ }^{36}$ and both diseases were associated with poor asthma control. In our study, scores in the anxiety and depression subscales of the HADS improved significantly at 6 months compared with scores at baseline, after a timely visit by the doctor. Also, anxiety and depression scores were higher (more distress) when there was discordance between patients and physicians and the physician underestimated the impact of the patient's disease. The amplitude of the difference in scores of the 10-item questionnaire between patients and physicians correlated significantly with anxiety and depression symptoms. The greater the discordance between patients' and physicians' opinions, the higher the degree of impairment due to 


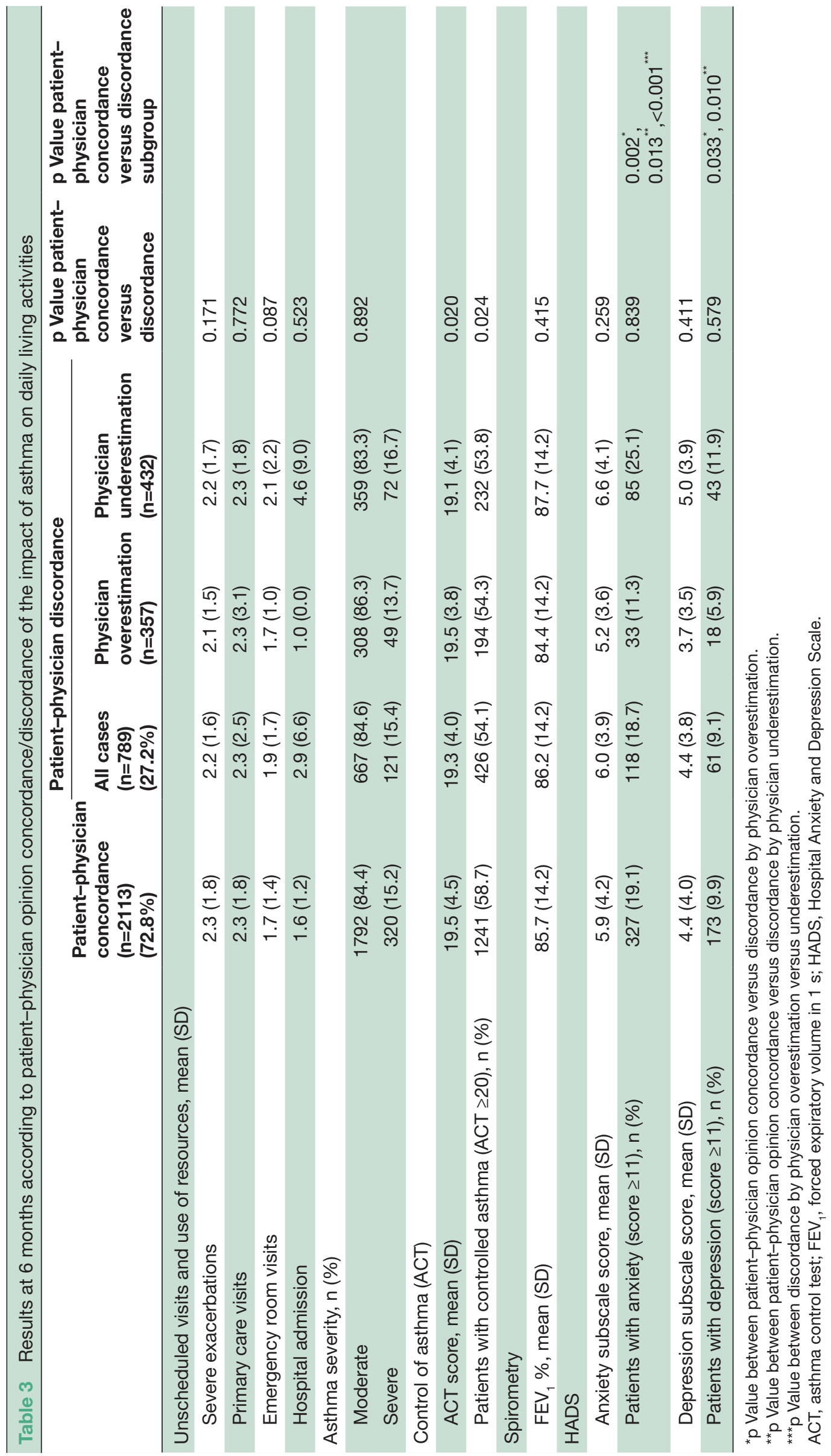


patients' psychiatric comorbidity. This finding suggests the influence of physicians in the control of asthma of their patients and also in the degree of asthma-related anxiety and depression. In a study that compared opinions and involved 319 psychiatrists and 957 patients diagnosed with depression, depressive symptoms related to circadian rhythms (except fatigue, anergy and insensitivity) perceived by more than $65 \%$ of patients surveyed were significantly underestimated by psychiatrists and only partially resolved with antidepressive medication. ${ }^{37}$ On the other hand, satisfaction with the results of treatment with antidepressants manifested by patients was lower than general satisfaction stated by psychiatrists. ${ }^{37}$ Other studies have also concluded that physicians evaluate differently the presence and impact of symptoms on daily activities of their patients and, in turn, the level of satisfaction and compliance with treatment. ${ }^{38-45}$

\section{Limitations and strengths}

This study has some limitations. First, we have not included other measurements or variables that may affect the degree of asthma control, such as treatment adherence, adjustment of maintenance treatment, patient's education or use of non-invasive methods of measurement of airway inflammation. Second, this study has a selection bias: both the pulmonologists and the patients volunteered to participate in the study. Third, the different medical specialists may have different perspectives on how to approach/educate/ treat patients with asthma. Finally, an important proportion of patients were active or previous smokers $(36.1 \%)$ and some might have overlapping symptoms of COPD-asthma that could influence outcomes. However, since the mean age of the population was 46.8 years, it is less likely that these patients had COPD. However, the large sample size of 2902 patients who completed the 6-month follow-up period gives strength to the study findings.

\section{CONCLUSIONS}

Patient-physician opinion discordance related to the impact of asthma on patients' daily activities may be contributing to lower symptomatic control and increased future risk, with a higher impact when physicians underestimate the impact of asthma on their patients.

Asthma education programmes should address patients' and doctors' discordances. Educational strategies to promote an optimal level of concordance between patients' and physicians' opinions and expectations should be pursued.

\section{Author affiliations}

${ }^{1}$ Service of Pneumology, Hospital de la Santa Ceu i Sant Pau, Institute of Sant Pau \& Biomedical Research (IBB Sant Pau), Universitat Autònoma de Barcelona, Centro de Investigación Biomédica en Red de Enfermedades Respiratorias (CIBERES), Barcelona, Spain

${ }^{2}$ Service of Pneumology, Complejo Hospitalario Universitario de Santiago de Compostela. Department of Medicine, University of Santiago de Compostela. Centro de Investigación Biomédica en Red de Enfermedades Respiratorias (CIBERES), Complejo Hospitalario Universitario de Santiago de Compostela, Santiago de Compostela, La Coruña, Spain
${ }^{3}$ Medical Advisor de Respiratorio, Mundipharma Farmaceuticals, Madrid Spain

${ }^{4}$ Department of Allergy, Hospital Universitario Fundación Jiménez Díaz. Centro delnvestigación Biomédica en Red de Enfermedades Respiratorias (CIBERES) Hospital Universitario Fundación Jiménez Díaz, Madrid, Spain

Acknowledgements The authors are grateful to Mundipharma Pharmaceuticals for logistic support and to Marta Pulido for editing the manuscript and editorial assistance.

Collaborators The CONCORD Study Group (ALBACETE): Callejas González, F; Jiménez López, J; Martínez Riaza, M; Moscardó Orenes, M; Prieto Montaño, P; Torrecillas Toro, M; (ALICANTE): Andreu Balaguer, C; Antón Girones, M; Baeza Martinez, C; Flores Martín, I; Gonzalez Delgado, P; Martos Calahorro, M; Mediero Carrasco, G; Rodríguez Pacheco, R; Vilella Tomás, V; (ALMERÍA): Mota Godoy, M; Zapata Yébenes, J; (ÁLAVA): Villarreal Balza De Vallejo, 0; (ASTURIAS): Alvarez Fernandez, J; Bazus Gonzalez, T; Castaño De Las Pozas, G; Diaz Donado, C; Díaz Angulo, S; Gala Ortiz, G; Requejo Mañana, B; (ÁVILA): Blanco Gonzalez, R; (BADAJOZ): Gómez Nieves, E; Marin Torrado, J; (BARCELONA): Dordal Culla, M; Juanola Pla, J; Lleonart Bellfill, R; Martos Velasco, J; Pinto Nogues, E; Rivera Ortun, M; Rubinstein Aguñin, P; Subira Farre, N; Valldeperas Combas, J; (BIZKAIA): Ansotegui Zubeldia, I; Bernaola Hortigüela, G; Ciruelos Ayuso, J; González Álvarez, G; Herrerias Peña, M; Lahuerta Castro, A; Losada Llorente, P; Marin Martinez, P; Marina Malanda, N; (BURGOS): Garcia Gonzalez, F; Peña Miguel, T; (CÁCERES): Hernandez Hernandez , M; Jimenez Timon, S; Porcel Carreño, S; (CÁDIZ): Alwakil Olbah, M; Arnedillo Muñoz, A; Chamorro Mohedad, J; Gutierrez Fernandez, D; Letran Camacho, A; Merinas Lopez, C; Millan Gonzalez, M; Niño Bernal, S; Fernandez Pellon, L; (CANTABRIA): Morchon Miguel, E; Ortiz Portal, F; Suárez Rodríguez, A; (CASTELLÓN): Modesto Alapont, M; Raducan , I; Salvador Segarra, M; (CIUDAD REAL): Galindo Bonilla, P; Mata Calderon, P; Mena Rodriguez, M; (CÓRDOBA): Lama Martinez, R; Martín Pérez, M; Morales Villarejo, M; (CORUÑA): Blanco Aparicio, M; Do Muíño Joga, M; Fontan Garcia-Boente, L; García Paz, V; Gonzalez Barcala, F; Nuñez Orjales, R; Rabade Castedo, C; Rico Diaz, M; (CUENCA): Moreno Fernandez, A; (GIRONA): Aparicio Español, S; Ruiz San Francisco, A; (GRANADA): Alcázar Navarrete, B; Cassini Gomez De Cadiz, L; Escribano Rodriguez, M; Florido Lopez, J; Lara Jiménez, M; Lopez Caballero, J; Martínez Ceres, M; Mayorgas Costoya, R; Morales García, C; Rojas Vilchez, M; Romero Ortiz, A; (GUADALAJARA): Beitia Mazuecos, J; Vega Castro, A; ((GUIPUZCOA): Labeguerie Arenaza, B; Lizarza Mendizabal, S; Perez Sampedro, I;(HUELVA): Valverde Vazquez, L; (HUESCA): Cegoñino De Sus, J; Compaired Villa, J; Ferrer Pargada, D; Herrero Jarque, J; (ILLES BALEARS): Chacon Patiño, M; Fuster Gomila, A; Nicolau Pastrie, F; (JAÉN): Almagro Lopez, J; (LEÓN): Benito Martinez, P; Velez Ruiz De Lobera, A; (LUGO): Carballada Gonzalez, F; Perez Carral, C; Veres Racamonde, A; (LLEIDA): Cervera Del Pino, M; Rozadilla Sacanell, J; (MADRID): Ali García, I; Anta Mejias, Y; Añíbarro Bausela, B; Arroyo Cozar, M; Barranco Sanz, P; Bobolea , I; Bueso Fernandez, A; De Santiago Delgado, E; Diaz Campos, R; Donado Uña, J; Feliu Vila, A; Gandolfo Cano, M; Garcia De Pedro, J; Garcimartin Galicia, M; González De Olano, D; Huertas Barbudo, B; López Viña, A; Losada Peña, A; Minguez Martin, G; Montoro De Francisco, A; Moreno Borque, R; Moro Moro, M; Ramirez Prieto, M; Reche Frutos, M; Rodriguez Jimenez, B; Rodríguez Rodríguez, M; Romero Ribate, D; Ruano Perez, F; Ruiz Hornillos, J; Sánchez López, P; Sola Martinez, F; Subiza Garrido-Lestache, J; Vasquez Gambasica, Z; Vila Albelda, C; (MÁLAGA): Alcazar Ramirez, J; De Luiz Martínez, G; García Núñez, I; Linde De Luna, F; Ortega Sáenz De Tejada, E; Padilla Galo, A; Rodriguez Martinez, R; Soria Esojo, M; (MURCIA): Andujar Espinosa, R; Avilés Inglés, M; Bernabeu Mora, R; Franco Campos, M; Peña Arellano, M; (NAVARRA): Alvarez Puebla, M; García Figueroa, B; Garrido Fernández, S; Olaguibel Rivera, J; Tabar Purroy, A; (OURENSE): Presedo Garazo, B: Varela Losada, S; (PALENCIA): García Villamuza, Y; (PALMAS,LAS) Cumplido Bonny, J; (PONTEVEDRA): Alvarez Sintes, R; Castro Landin, J; Cobas Paz, A; Corbacho Abelaira, M; Iglesias Rio, F; Pallarés Sanmartín, A; Picans Picans, I; Regueiro Moreira, A;(RIOJA): Tejedor Romera, R; (SALAMANCA): Igea Aznar, J; Muñoz Bellido, F; Rodriguez Hernandez, M; (SANTA CRUZ DE TENERIFE): González Perez, R; Izaguirre Flores, H; (SEVILLA): Alvarez Gutierrez, F; Cimbollek, S; De Luque Piñana, V; Medina Gallardo, J; Moreno Garcia, V; Orta Cuevas, J; Puente Crespo, Y; Quiralte Enriquez, J; Serrano Dominguez, P; (TARRAGONA): Sotorra Elias, Oे; (TERUEL): Muñoz Pamplona, M; (TOLEDO): Jimenez Lara, M; Moral De Gregorio, A; (VALENCIA): Alvariño Martin, M; Ballester Canelles, M; Burches Baixauli, E; Catalán Serra, P; Climent Gregori, M; Cordero Rodriguez, P; De Las Marinas Alvarez, M; Díaz Palacios, M; El-Qutob López, D; Greses Giner, J; Herrera Lara, S; Jorro Martínez, G; Liñana Santafé, J; Lloris Bayo, A; Martinez Moragon, E; Molero Sancho, I; Montoro Lacomba, J; Naval Sendra, E; Navarro Seisdedos, L; Orosa Bertol, B; Robles Iniesta, A; Ruiz Cubillan, J; Sánchez-Toril López, F; Saura Vinuesa, A; (VALLADOLID): Alonso Gomez, A; De Frutos Arribas, J; Macias Fernandez, E; Sanchez Alonso, A; (ZARAG0ZA): Colás Sanz, C; Domínguez Fuentes, M; Garcés Sotillos, M; Segura Arazuri, N. 
Contributors All authors made substantial contributions to the study. ACL: enrolled patients and wrote the first draft of the manuscript; VP and JS: generated the hypothesis, designed the study, built the database and performed statistical analysis; F-JG-B and TF-S: participated in data interpretation and manuscript writing.

Funding Mundipharma Pharmaceuticals had no involvement in study design; in the collection, analysis and interpretation of data; in the writing of the report; or in the decision to submit the paper for publication. The authors confirm that all personal identities have been removed or disguised so that participants are not identifiable.

Competing interests ACL was consultant for Mundipharma Pharmaceuticals in relation to the present study. VP in the last 3 years received honoraria for speaking at sponsored meetings from Chiesi, Esteve Laboratories, GlaxoSmithKline (GSK), Novartis, Orion and Pfizer; received assistance with travel to meetings from Chiesi and Novartis; acted as a consultant for Mundipharma Pharmaceuticals, Orion and Teva; and received funding/grant support for research projects from a variety of Government agencies and not-for-profit foundations as well as AstraZeneca, Chiesi, Menarini, GSK and ALK. F-JG-B: no conflicts to be declared. TF-S was a full-time employee of Mundipharma Pharmaceuticals. JS served as a consultant to Thermofisher, MSD, Novartis, Genentech, Sanofi, Leti, Roche, FAES FARMA, Mundipharma, and GSK; received lecture fees from Novartis, GSK, Stallergenes, LETI and FAES FARMA and grant support for research from Thermofisher.

Patient consent Obtained.

Ethics approval the protocol was approved by the Ethics Committee of the participating hospitals of the study coordinators.

Provenance and peer review Not commissioned; externally peer reviewed.

Data sharing statement All data are available to the public for a maximum period of 5 years after the publication of this article.

Open Access This is an Open Access article distributed in accordance with the Creative Commons Attribution Non Commercial (CC BY-NC 4.0) license, which permits others to distribute, remix, adapt, build upon this work non-commercially, and license their derivative works on different terms, provided the original work is properly cited and the use is non-commercial. See: http://creativecommons.org/ licenses/by-nc/4.0/

(c) Article author(s) (or their employer(s) unless otherwise stated in the text of the article) 2017. All rights reserved. No commercial use is permitted unless otherwise expressly granted.

\section{REFERENCES}

1. GEMA. Española para el manejo del asma. Arch Bronconeumol 2009;45(Suppl 7):1-35. http://www.gemasma.com

2. BTS/SIGN. British guideline on the management of asthma. British Thoracic Society/Scottish Intercollegiate Guidelines Network. Thorax 2008;6:1-121.

3. Global Initiative for Asthma (GINA). Global Strategy for Asthma Management and Prevention. 2014. http://www.ginasthma.org

4. Papaioannou Al, Kostikas K, Zervas E, et al. Control of asthma in real life: still a valuable goal? Eur Respir Rev 2015;24:361-9.

5. Fletcher M, Hiles D. Continuing discrepancy between patient perception of asthma control and real-world symptoms: a quantitative online survey of 1,083 adults with asthma from the UK. Prim Care Respir J 2013;22:431-8.

6. Yıldız F. ASIT Study Group. Factors influencing asthma control: results of a real-life prospective observational asthma inhaler treatment (ASIT) study. J Asthma Allergy 2013;6:93-101.

7. Moffat M, Cleland J, van der Molen T, et al. Sub-optimal patient and physician communication in primary care consultations: its relation to severe and difficult asthma. Prim Care Respir J 2006;15:159-65.

8. Arora NK, Ayanian JZ, Guadagnoli E. Examining the relationship of patients' attitudes and beliefs with their self-reported level of participation in medical decision-making. Med Care 2005;43:865-72.

9. Irwin RS, Richardson ND. Patient-focused care: using the right tools. Chest 2006;130(1 Suppl):73S-82.

10. Moffat M, Cleland J, van der Molen T, et al. Poor communication may impair optimal asthma care: a qualitative study. Fam Pract 2007;24:65-70.

11. Urrutia I, Plaza V, Pascual S, et al. Asthma control and concordance of opinions between patients and pulmonologists. J Asthma 2013;50:877-83.

12. Horne R. Compliance, adherence, and concordance: implications for asthma treatment. Chest 2006;130(1 Suppl):65S-72.
13. Horne R, Price D, Cleland J, et al. Can asthma control be improved by understanding the patient's perspective? BMC Pulm Med 2007:7:7-8.

14. Ponte EV, Petroni J, Ramos DC, et al. [Perception of asthma control in asthma patients]. J Bras Pneumol 2007;33:635-40.

15. Heiner MM. Key barriers to optimal management of adult asthma in Australia: physician and patient perspectives. Curr Med Res Opin 2007;23:1799-807.

16. Ciprandi G, Schiavetti I, Rindone E, et al. The impact of anxiety and depression on outpatients with asthma. Ann Immunol 2015;115:408-14.

17. Urrutia I, Aguirre U, Pascual S, et al. Impact of anxiety and depression on disease control and quality of life in asthma patients. $J$ Asthma 2012;49:201-8.

18. Di Marco F, Verga M, Santus P, et al. Close correlation between anxiety, depression, and asthma control. Respir Med 2010;104:22-8.

19. Kullowatz A, Kanniess F, Dahme B, et al. Association of depression and anxiety with health care use and quality of life in asthma patients. Respir Med 2007;101:638-44.

20. American Thoracic Society. Standards for the diagnosis and care of patients with chronic obstructive pulmonary disease (COPD) and asthma. Am Rev Respir Dis 1987;136:225-44.

21. Vega JM, Badia X, Badiola C, et al. Validation of the Spanish version of the Asthma Control Test (ACT). J Asthma 2007;44:867-72.

22. Roca J, Sanchis J, Agusti-Vidal A, et al. Spirometric reference values from a Mediterranean population. Bull Eur Physiopathol Respir 1986;22:217-24.

23. Zigmond AS, Snaith RP. The Hospital Anxiety and Depression Scale. Acta Psychiatr Scand 1983;67:361-70.

24. Picado C, Badiola C, Perulero N, et al. Validation of the Spanish version of the Asthma Control Questionnaire. Clin Ther 2008;30:1918-31.

25. Pérez-Yarza EG, Badía X, Badiola C, et al. Development and validation of a questionnaire to assess asthma control in pediatrics. Pediatr Pulmonol 2009;44:54-63.

26. González Barcala FJ, de la Fuente-Cid R, Alvarez-Gil R, et al. [Factors associated with asthma control in primary care patients: the CHAS study]. Arch Bronconeumol 2010;46:358-63.

27. Olaguibel JM, Quirce S, Juliá B, et al. Measurement of asthma control according to Global Initiative for Asthma guidelines: a comparison with the Asthma Control Questionnaire. Respir Res 2012;13:50.

28. Peters SP, Ferguson G, Deniz Y, et al. Uncontrolled asthma: a review of the prevalence, disease burden and options for treatment. Respir Med 2006;100:1139-51.

29. Price $D$, Fletcher $M$, van der Molen T. Asthma control and management in 8,000 European patients: the REcognise Asthma and LInk to Symptoms and Experience (REALISE) survey. NPJ Prim Care Respir Med 2014;24:14009.

30. González-Gutiérrez MV, Guerrero Velázquez J, Morales García $\mathrm{C}$, et al. Predictive model for anxiety and depression in Spanish patients with stable chronic obstructive pulmonary disease. Arch Bronconeumol 2016;52:151-7.

31. Montserrat-Capdevila J, Godoy P, Marsal JR, et al. Overview of the impact of depression and anxiety in chronic obstructive pulmonary disease. Lung 2017;195

32. Uchmanowicz I, Jankowska-Polanska B, Motowidlo U, et al. Assessment of illness acceptance by patients with COPD and the prevalence of depression and anxiety in COPD. Int J Chron Obstruct Pulmon Dis 2016;11:963-70.

33. Soler-Cataluña JJ, Sauleda J, Valdés L, et al. Prevalence and perception of 24-hour symptom patterns in patients with stable chronic obstructive pulmonary disease in Spain. Arch Bronconeumol 2016:52:308-15.

34. Iyer AS, Bhatt SP, Garner JJ, et al. Depression is associated with readmission for acute exacerbation of chronic obstructive pulmonary disease. Ann Am Thorac Soc 2016;13:197-203.

35. Goodwin RD, Pine DS. Respiratory disease and panic attacks among adults in the United States. Chest 2002;122:645-50.

36. Ciprandi G, Schiavetti I, Rindone E, et al. The impact of anxiety and depression on outpatients with asthma. Ann Allergy Asthma Immunol 2015;115:408-14.

37. San Molina L, Montes-Rodríguez JM, Caballero-Martínez F, et al. Depressive symptoms associated with changes in circadian rhythms. Concordance in perception between doctor and patient, clinical impact and its response to current antidepressant drugs. Rev Psiquiatr Salud Ment 2011;4:19-27.

38. Coulter A. Patients' views of the good doctor. Doctors have to earn patient's trust. BMJ 2002;325:668-9.

39. Ford S, Schofield T, Hope T. Barriers to the evidence-based patient choice (EBPC) consultation. Patient Educ Couns 2002;47:179-85. 
40. Harrington J, Noble LM, Newman SP. Improving patients' communication with doctors: a systematic review of intervention studies. Patient Educ Couns 2004:52:7-16.

41. Haynes RB, Devereaux PJ, Guyatt GH. Physicians' and patients' choices in evidence based practice. BMJ 2002;324:1350.

42. Holmes-Rovner M, Valade D, Orlowski C, et al. Implementing shared decision-making in routine practice: barriers and opportunities. Health Expect 2000;3:182-91.
43. Stevenson FA, Cox K, Britten N, et al. A systematic review of the research on communication between patients and health care professionals about medicines: the consequences for concordance. Health Expect 2004;7:235-45.

44. Krupat E, Rosenkranz SL, Yeager CM, et al. The practice orientations of physicians and patients: the effect of doctor-patient congruence on satisfaction. Patient Educ Couns 2000;39:49-59.

45. Bowling A, Ebrahim S. Measuring patients' preferences for treatment and perceptions of risk. Qual Health Care 2001;10(Suppl 1)i2-8. 